ISSN 2073-4344

www.mdpi.com/journal/catalysts

Article

\title{
The Role of Ozone in the Reaction Mechanism of a Bare Zeolite-Plasma Hybrid System
}

\author{
Yoshiyuki Teramoto *, Hyun-Ha Kim, Nobuaki Negishi and Atsushi Ogata \\ National Institute of Advanced Industrial Science and Technology (AIST), \\ 16-1 Onogawa, Tsukuba 305-8569, Japan; E-Mails: hyun-ha.kim@aist.go.jp (H.-H.K.); \\ n-negishi@aist.go.jp (N.N.); atsushi-ogata@aist.go.jp (A.O.) \\ * Author to whom correspondence should be addressed; E-Mail: yoshiyuki-teramoto@aist.go.jp; \\ Tel.: +81-29-861-8715; Fax: +81-29-861-8866.
}

Academic Editor: Jean-François Lamonier

Received: 19 February 2015 / Accepted: 4 May 2015 / Published: 11 May 2015

\begin{abstract}
We investigated the reaction mechanism of a metal-unloaded zeolite-plasma hybrid system for decomposition of toluene at room temperature. Short-lived radicals and fast electrons did not contribute substantially to the reaction mechanism of toluene decomposition in the zeolite-plasma hybrid system. The main factor enhancing the reaction mechanism was gas-phase $\mathrm{O}_{3}$ directly reacting with toluene adsorbed onto the zeolite (the Eley-Rideal mechanism). $\mathrm{CO}_{2}$ selectivity was not improved by using $\mathrm{H}-\mathrm{Y}$ zeolite due to its low ability to retain the active oxygen species formed by $\mathrm{O}_{3}$. The gas-phase $\mathrm{O}_{3}$ reacted with adsorbed toluene to form a ring cleavage intermediate that was slowly converted into formic acid. The decomposition rate of formic acid was much lower than that of toluene on the H-Y surface.
\end{abstract}

Keywords: plasma; hybrid system; zeolite; VOC

\section{Introduction}

Non-thermal plasma processes have attracted significant interest as promising technologies for decomposing volatile organic compounds (VOCs) [1]. Over the last decade, research has focused on improving the process efficiency of decomposition of VOCs using various plasma reactors such as pulsed corona [2-4], ferroelectric pellet packed-bed discharge [5], silent (dielectric barrier) discharge [6], and surface discharge [7,8] reactors. The feasibility of plasma processes is limited by 
energy efficiency and formation of toxic by-products. To improve energy efficiency and $\mathrm{CO}_{2}$ selectivity, catalyzed hybrid plasma reactors have been designed [9-11]. For example, it has been reported that the combination of dielectric barrier discharge and a metal loaded catalyst enhances trichloroethylene decomposition and $\mathrm{CO}_{2}$ selectivity [12,13]. Loading of active metals not only enhances $\mathrm{CO}_{2}$ selectivity for various VOCs $[9,14,15]$, but also improves plasma coverage on the surface [16]. We have also proposed a non-thermal plasma reactor combined with a catalyst [8,17] and cyclic plasma operation [18]. Plasma induced surface oxygen species on metal nanoparticles play a significant role in improvement of the process $[19,20]$. In particular, $\mathrm{O}_{3}$ enhances formation of active oxygen species on the catalyst surface. Manganese oxides $\left(\mathrm{MnO}_{x}\right)$ are well known as promising catalysts for decomposition of $\mathrm{VOCs}_{3}$ by $\mathrm{O}_{3}$ at low temperatures through the Langmuir-Hinshelwood (L-H) mechanism, as follows [21]:

$$
\begin{gathered}
\mathrm{O}_{3}+* \rightarrow \mathrm{O}_{2}+* \mathrm{O}_{\text {ads }} \\
* \mathrm{O}_{\text {ads }}+\mathrm{VOC}_{\text {ads }} \rightarrow \mathrm{CO}_{x}+\mathrm{H}_{2} \mathrm{O}+*
\end{gathered}
$$

where $*$ is an active sites on the catalyst and ${ }^{*} \mathrm{O}_{\text {ads }}$ is the active oxygen species on the catalyst. Previous studies have reported that metal nanoparticles on zeolite strongly retain the active oxygen species formed by plasma compared with bare zeolite. We previously investigated active oxygen species formed by plasma on a silver nanoparticle-loaded zeolite [22]. The amount of active oxygen fixed onto the catalyst surface by $\mathrm{O}_{2}$ plasma was approximately proportional to the square of the amount of supported silver. Thus, most of the active oxygen was present on the silver surface. Interestingly, the ozone demand factor $\left(\mathrm{DFO}_{3}=\Delta\left[\mathrm{O}_{3}\right] / \Delta[\right.$ toluene $]$ ), i.e., the amount of ozone required for oxidation of toluene of bare zeolite (ZSM-5), was half that of silver-loaded zeolite [23]. Smaller DFo3 values correlate with better performance during ozone-assisted catalysis of VOCs. These findings suggest that the supported metal does not necessarily improve the efficiency of the plasma hybrid system and that performance improvements in that system cannot be explained solely by surface reactions of active oxygen species formed by $\mathrm{O}_{3}$ (the L-H mechanism).

In this study, we focused on reaction mechanisms of a metal-unloaded zeolite in a plasma hybrid system for toluene decomposition. The role of metal nanoparticles has been studied by several research groups and has been found to be important in VOC removal, affecting decomposition efficiency, the carbon balance, and $\mathrm{CO}_{2}$ selectivity. However, the role of supports (e.g., without active metals) has not been well studied in terms of interaction with plasma. The role of zeolite in the toluene decomposition process was investigated by changing the position of the zeolite in the plasma reactor. The reaction mechanisms of toluene decomposition in the gas phase and on the zeolite surface were studied using gaseous and surface FT-IR analyses.

\section{Results and Discussion}

\subsection{Role of Zeolites in the Plasma Hybrid System}

Energy efficiency in the decomposition of VOCs was enhanced by using a zeolite-hybrid plasma reactor [18]. Improvements in efficiency differed widely depending on the type of zeolite and its position in the reactor. Table 1 summarizes the performance of the zeolites in toluene oxidation, and their basic properties. Decomposition efficiency in the downstream position was 3.7 times higher than that in a 
conventional reactor, while that in the upstream position was 1.2-1.5 times higher. Additionally, decomposition efficiency in the downstream position was significantly affected by the type of zeolite, compared with upstream. The dependence of the decomposition efficiency on the position of the zeolite suggests that improvements in performance cannot be explained solely by activation of the zeolite surface by plasma.

Table 1. Decomposition efficiency in hybrid plasma reactors and the properties of zeolites.

\begin{tabular}{|c|c|c|c|c|c|c|c|c|c|c|c|c|c|}
\hline \multirow{2}{*}{ Zeolite } & \multirow{2}{*}{\multicolumn{2}{|c|}{$\begin{array}{c}\mathrm{C}_{7} \mathrm{H}_{8} \text { decomposition (\%) } \\
\text { Upstream:Downstream }\end{array}$}} & \multicolumn{6}{|c|}{ Product selectivity (\%) } & \multirow{2}{*}{\multicolumn{2}{|c|}{$\begin{array}{c}\text { Carbon } \\
\text { balance } \\
(\%)\end{array}$}} & \multirow{2}{*}{$\begin{array}{c}\text { Surface } \\
\text { area } \\
\left(\mathrm{m}^{2} / \mathrm{g}\right)\end{array}$} & \multirow{2}{*}{$\mathrm{SiO}_{2} / \mathrm{Al}_{2} \mathrm{O}_{3}$} & \multirow{2}{*}{$\begin{array}{c}\text { Channel } \\
(\AA ̊)\end{array}$} \\
\hline & & & \multicolumn{2}{|c|}{ CO } & \multicolumn{2}{|c|}{$\mathrm{CO}_{2}$} & \multicolumn{2}{|c|}{ НСООН } & & & & & \\
\hline None & & & & & & & & & & & - & - & - \\
\hline $\mathrm{Na}-\mathrm{Y}$ & 21 & 52 & 36 & 33 & 56 & 63 & 8 & 4 & 95 & 92 & 750 & 3.1 & 7.4 \\
\hline $\mathrm{H}-\mathrm{Y}(1)$ & 18 & 55 & 41 & 45 & 52 & 47 & 7 & 8 & 97 & 99 & 650 & 1.9 & 7.4 \\
\hline $\mathrm{H}-\mathrm{Y}(2)$ & 20 & 50 & 47 & 42 & 46 & 51 & 7 & 7 & 98 & 96 & 520 & 5.6 & 7.4 \\
\hline MOR & 23 & 35 & 46 & 42 & 45 & 52 & 9 & 6 & 97 & 96 & 460 & 15.2 & $6.7 \times 7.0$ \\
\hline FER & 19 & 20 & 38 & 33 & 49 & 65 & 13 & 2 & 96 & 99 & 270 & 17.9 & $4.3 \times 5.5$ \\
\hline
\end{tabular}

Figure 1 shows the relationship between the amount of toluene adsorbed and decomposition efficiency (normalized to that of a reactor without zeolites). In general, the surface area greatly affects the adsorption capacity and decomposition of VOCs. In a previously reported ozone-assisted catalyst system, the rate of benzene oxidation linearly increased with the specific surface area of the $\mathrm{MnO}_{x}$-loading catalyst, regardless of the type of catalyst support [24]. In the present study, the amount of toluene ( $\sim 6 \AA$ ) adsorbed by ferrierite (FER) was small and limited to the surface due to the micropore size $\left(4.3 \times 5.5 \AA^{2}\right)$ of FER.

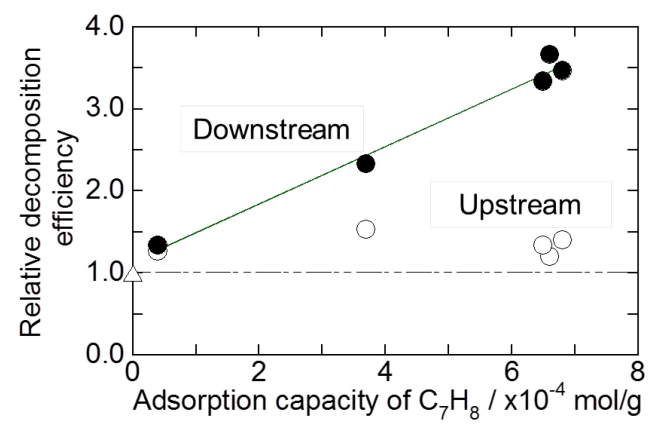

Figure 1. Relationship between the decomposition efficiency and adsorption capacity for toluene.

The decomposition efficiency of the downstream configuration was linearly proportional to the adsorption capacity (Figure 1). On the other hand, that of the upstream configuration was near constant. If the toluene adsorbed in the internal areas of the zeolite was decomposed by short-lived radicals and fast electrons, the decomposition efficiency would not depend on the zeolite position. We conclude that reactions between toluene adsorbed onto the zeolite and short-lived radicals or fast electrons did not contribute to improvements in decomposition efficiency. One possible explanation is the limited area of plasma for bare zeolite compared to metal-loaded zeolites; plasma mainly formed at the points of contact with the zeolite pellets [16]. This limited plasma area reduced effective interactions at the surface of the zeolite. These results confirm the important contribution of metal nanoparticles to both plasma properties and catalytic performance. 
In addition, the diffusion lengths of short-lived radicals $(\mathrm{O}$ and $\mathrm{OH})$ and fast electrons are $<100 \mu \mathrm{m}$ at atmospheric pressure. Thus, short-lived radicals and fast electrons had limited effect in this system.

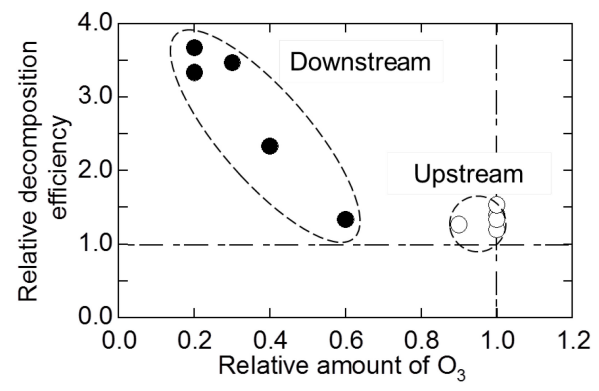

Figure 2. Relationship between the relative decomposition efficiency and relative amount of ozone.

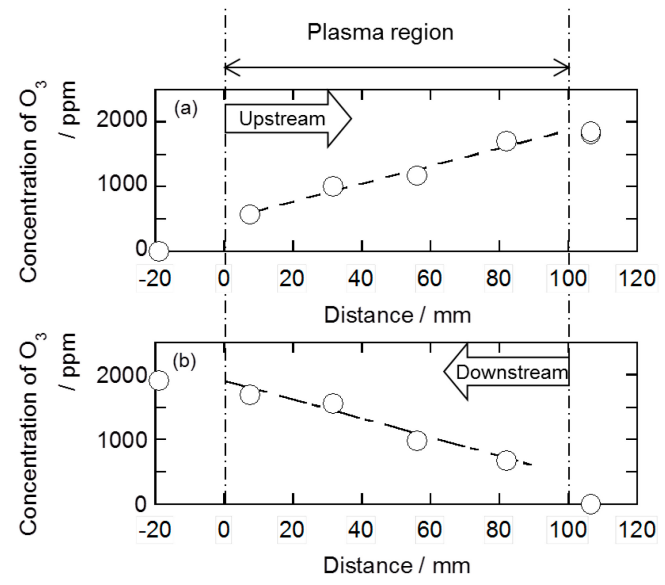

Figure 3. Ozone distribution in a conventional plasma reactor: (a) upstream configuration and (b) downstream configuration.

Ozone has a long diffusion length $(>10 \mathrm{~mm})$ due to its long lifetime, and can reach the inner area of micropores. Figure 2 shows the decomposition efficiency as a function of the outlet $\mathrm{O}_{3}$ concentration, normalized to that of a reactor without zeolites. In the downstream position, the $\mathrm{O}_{3}$ concentration was affected by the type of zeolite and decreased with increasing decomposition efficiency. Therefore, $\mathrm{O}_{3}$ was consumed approximately linearly with toluene oxidation. In the upstream position, there were no significant differences in $\mathrm{O}_{3}$ concentration or decomposition efficiency among the zeolite types. This can be explained by the $\mathrm{O}_{3}$ concentration at the entrance of the plasma reactor. The distribution of $\mathrm{O}_{3}$ concentrations in the reactor tube were measured using a dedicated reactor (shown in section 3.2.). Figure 3a,b shows the distribution of $\mathrm{O}_{3}$ in an unfilled reactor under dry air flow (without toluene or $\mathrm{H}_{2} \mathrm{O}$ ) in the upstream and downstream configurations, respectively. The $\mathrm{O}_{3}$ concentration increased linearly with distance from the entrance of the reactor in both directions. When $1.0 \mathrm{~g}$ of $\mathrm{H}-\mathrm{Y}$ was placed in the upstream or downstream position, the $\mathrm{O}_{3}$ concentration remained constant in the zeolite-filled region (Figure 4a,b)). These results were also observed for other zeolite types. Thus, formation of $\mathrm{O}_{3}$ was strongly suppressed in the zeolites-filled region. Based on these results, the low decomposition efficiency of the upstream configuration was likely due to a low $\mathrm{O}_{3}$ concentration, while the high efficiency of the downstream configuration was due to a high $\mathrm{O}_{3}$ concentration. Therefore, adsorbed 
toluene in the internal area of the zeolite was manly decomposed by $\mathrm{O}_{3}$. In addition to reactions (1) and (2), the following reaction represents this mechanism:

$$
* \mathrm{VOC}_{\mathrm{ads}}+\mathrm{O}_{3} \rightarrow \mathrm{CO}_{x}+\mathrm{H}_{2} \mathrm{O}+*
$$

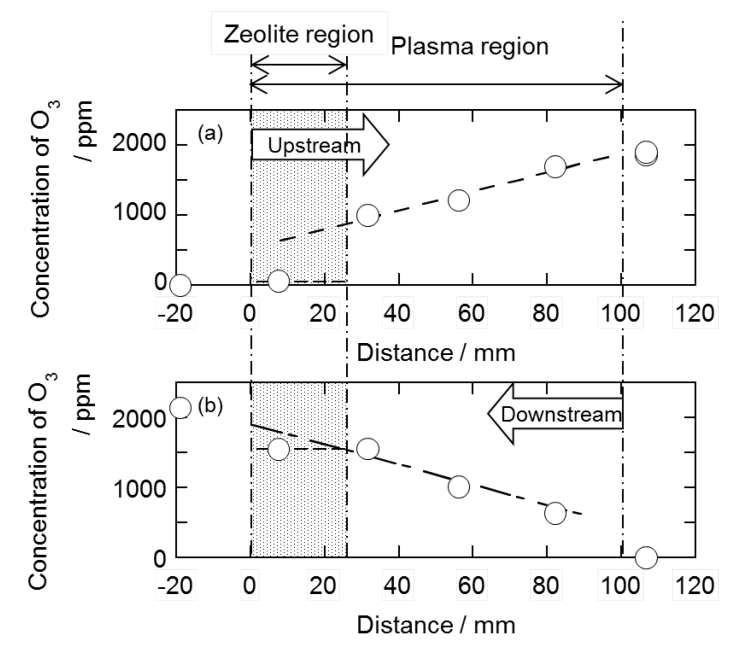

Figure 4. Relationship between the decomposition efficiency and the adsorption of ozone: (a) upstream configuration and (b) downstream configuration.

In reactions (1) and (2), $\mathrm{O}_{3}$ initially decomposes at the zeolite surface. Figure 5 shows the outlet concentration of $\mathrm{O}_{3}$ in the downstream reactor filled with 1.0-3.0 g of H-Y. No decomposition of $\mathrm{O}_{3}$ was observed for any case. Thus, $\mathrm{H}-\mathrm{Y}$ has little ability to decompose $\mathrm{O}_{3}$ and form active oxygen species on its surface. Therefore, the main process involved in toluene decomposition is likely direct reaction of gas phase $\mathrm{O}_{3}$ with toluene adsorbed onto H-Y, i.e., the Eley-Rideal (E-R) mechanism. This process is different from that for other types of zeolites and metal-loaded zeolites, i.e., the L-H mechanism. For example, active oxygen species formed by $\mathrm{O}_{3}$ on the MCM-41 and MS-13X surfaces significantly contributed to VOC decomposition [25,26]. These active oxygen species on the catalyst surface are consumed in reactions with VOCs, $\mathrm{O}_{3}$, O, etc. [27-29]. In other words, some of the active oxygen species $\left(=\mathrm{O}_{3}\right)$ form unwanted byproducts in the L-H process, unlike in E-R. Therefore, in the E-R process, the $\mathrm{H}-\mathrm{Y}$ zeolite has the potential for achieving low DFo3 in VOC decomposition.

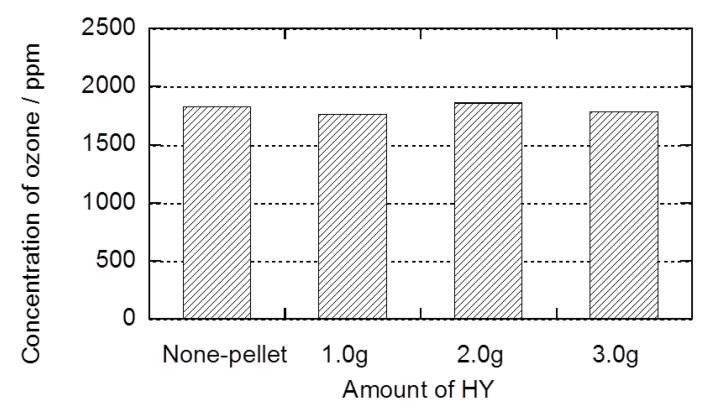

Figure 5. Concentration of ozone in the downstream reactor with amount of H-Y(1).

$\mathrm{CO}_{2}$ selectivity was similar between the H-Y filled and unfilled reactors (Table 1). On the other hand, production of formic acid was lower for the $\mathrm{H}-\mathrm{Y}$ filled reactors. Considering the role of $\mathrm{O}_{3}$ in this system (reaction (3)), it may be difficult for gaseous $\mathrm{O}_{3}$ to oxidize the adsorbed $\mathrm{CO}$ to $\mathrm{CO}_{2}$, unlike for toluene 
and formic acid. Generally, in a plasma-catalyst hybrid system, bare zeolite contributes little to oxidization of $\mathrm{CO}$. Metal-loaded zeolites significantly improves $\mathrm{CO}_{2}$ selectivity due to surface reaction with the active oxygen species formed by $\mathrm{O}_{3}$, most of which are present on the silver surface of the catalyst [22]. Thus, active oxygen species on the metal surface contribute greatly to improvements in $\mathrm{CO}_{2}$ selectivity. The $\mathrm{H}-\mathrm{Y}$ zeolite cannot easily retain active oxygen species on its surface through reactions with $\mathrm{O}_{3}$, leading to low $\mathrm{CO}_{2}$ selectivity.

Higher concentrations of VOCs result in higher energy efficiencies for removal [30]. Kuroki et al. [31] reported that adsorbed toluene desorbed easily by DC pulsed plasma discharge, resulting in an increase in the concentration of VOCs. Although this experimental result using standard adsorbents cannot be directly compared with zeolites, if such an effect occurred in our system, the efficiency in the upstream reactor should be nearly the same as that in the downstream one. However, efficiency in the downstream configuration was much higher than that in the upstream reactor. This suggested that enhancement due to desorption of toluene from the zeolite was negligible.

The hydrophilicity of zeolite depends on the $\mathrm{SiO}_{2} / \mathrm{Al}_{2} \mathrm{O}_{3}$ ratio and affects the performance of thermal catalytic processes. Generally, hydrophilicity decreases with increasing $\mathrm{SiO}_{2} / \mathrm{Al}_{2} \mathrm{O}_{3}$ ratio. However, the difference in hydrophilicity between $\mathrm{H}-\mathrm{Y}(1)$ and $\mathrm{H}-\mathrm{Y}(2)$ did not affect decomposition efficiency in our system (Table 1), unlike for thermal catalytic processes.

\subsection{Decomposition of Toluene Adsorbed onto the Zeolites by $\mathrm{O}_{3}$}

Figure 6a,b shows spectra for toluene adsorbed onto H-Y and FER, respectively, measured 10 min after introducing $200 \mathrm{ppm}$ of toluene in $\mathrm{N}_{2}$. Figure $6 \mathrm{c}$ also shows the spectrum for toluene in the gas phase as a reference. IR peaks assigned to the aromatic ring were observed between 2000 and $1750 \mathrm{~cm}^{-1}$ in both Figure 6a,b. These peak positions were shifted compared with those in the gas phase. Table 2 summarizes the IR peaks for toluene in both the gas and liquid phases. The adsorption peaks near $3000 \mathrm{~cm}^{-1}$ were assigned to the $\mathrm{CH}_{3}$ group of toluene and those at $2000-1700 \mathrm{~cm}^{-1}$ were assigned to the $\mathrm{C}-\mathrm{H}$ bonds in the aromatic ring. The shift in peaks for toluene adsorbed onto the zeolite is due to the perturbation of the $\pi$-electric system by adsorption onto the H-Y zeolite. These peaks were assigned to toluene physically adsorbed onto the solid surface, because they completely disappeared upon heating the sample to $200{ }^{\circ} \mathrm{C}$. The peak signal for toluene on FER was much smaller than that on H-Y, because the adsorption capacity of FER for toluene is limited due to its small micropore size.

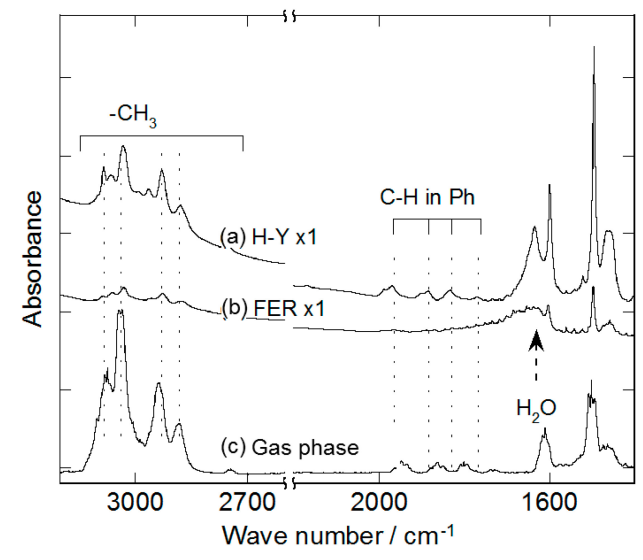

Figure 6. Infrared spectra for toluene (a) on H-Y(1) zeolite, (b) on FER, and (c) in the gas phase. 
Table 2. Wave number of IR peaks for toluene in gas phase, in the liquid film, and on H-Y.

\begin{tabular}{cccc}
\hline Bond & Gas phase & Liquid film & on H-Y \\
\hline \multirow{3}{*}{$\mathrm{C}-\mathrm{H}$ in $\mathrm{Ph}$} & 3101 & 3087 & 3083 \\
& 3076 & 3062 & 3065 \\
& 3037 & 3026 & 3031 \\
\hline \multirow{3}{*}{$\mathrm{C}-\mathrm{H}$ in $\mathrm{CH}_{3}$} & - & 2948 & 2963 \\
& 2938 & 2920 & 2928 \\
& 2881 & 2873 & 2879 \\
\hline \multirow{3}{*}{$\mathrm{C}-\mathrm{H}$ in $\mathrm{Ph}$} & 1942 & 1942 & 1969 \\
& 1856 & 1858 & 1884 \\
& 1801 & 1803 & 1832 \\
& 1732 & - & 1772 \\
\hline \multirow{3}{*}{$\mathrm{C}-\mathrm{C}$ in $\mathrm{Ph}$} & 1611 & 1605 & 1599 \\
& - & 1524 & - \\
& 1500 & 1496 & 1495 \\
& 1463 & 1451 & 1457 \\
\hline & Infra-red DB & SDBS & this work \\
\hline
\end{tabular}

The reactivity of toluene adsorbed onto $\mathrm{H}-\mathrm{Y}$ was then investigated. Initially, toluene was adsorbed onto the $\mathrm{H}-\mathrm{Y}$ sample for $10 \mathrm{~min}$ (Figure $7 \mathrm{a}$ ). $\mathrm{N}_{2}$ gas was then supplied to remove the gas phase toluene from the reactor. A mixture of $400 \mathrm{ppm} \mathrm{O}_{3}$ in $\mathrm{O}_{2}$ was then introduced and the FT-IR spectrum was recorded (Figure $7 \mathrm{~b}-\mathrm{f}$ ). The IR peaks for toluene disappeared immediately after $\mathrm{O}_{3}$ introduction, in less than 1 min. In contrast, IR peaks at 1390, 1630 and $1725 \mathrm{~cm}^{-1}$ appeared and their intensities increased for $40 \mathrm{~min}$ after $\mathrm{O}_{3}$ introduction. These peaks were assigned to formic acid ( $\left.\mathrm{HCOOH}\right)$. These results suggest that gas-phase $\mathrm{O}_{3}$ reacted with adsorbed toluene to form ring cleavage intermediate that was slowly converted to formic acid. We anticipate that the performance of the zeolite-plasma hybrid system could be improved by increasing the operating temperature, because the decomposition rate of formic acid is significantly affected by temperature [18].

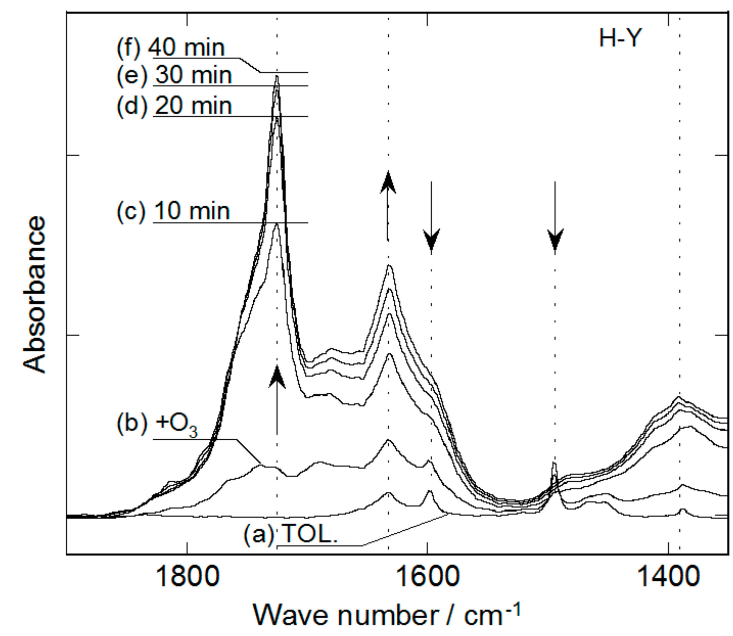

Figure 7. Infrared spectra for toluene decomposition on H-Y(1): (a) toluene adsorbed onto $\mathrm{H}-\mathrm{Y}$; after addition of $\mathrm{O}_{3}$ for (b) 0, (c) 10, (d) 20, (e) 30, and (f) $40 \mathrm{~min}$. 
A distinctive peak for the active oxygen species formed by $\mathrm{O}_{3}$ on MCM-41 and MS-13X was observed at around $1380 \mathrm{~cm}^{-1}[25,26]$. In the present experiment, this peak was not observed. This result supports the observation that the H-Y zeolite does not retain active oxygen species on its surface through reaction with $\mathrm{O}_{3}$.

Figure 8 shows IR spectra for formic acid adsorbed to $\mathrm{H}-\mathrm{Y}$ for $10 \mathrm{~min}$ under $\mathrm{HCOOH}(200 \mathrm{ppm}) / \mathrm{N}_{2}$ flow. The observed peaks were assigned to the carboxylic acid group (-COOH). The peak positions in the spectra and the profiles for formic acid adsorbed onto H-Y (Figure 8b) were in good agreement with those for toluene adsorbed onto $\mathrm{H}-\mathrm{Y}$ treated with $\mathrm{O}_{3}$ (Figure 7c-f). Therefore, the peaks in Figure 7c-f can be assigned to formic acid. When a mixture of 400 ppm $\mathrm{O}_{3}$ in $\mathrm{O}_{2}$ was introduced for 10 min, the peak at $1725 \mathrm{~cm}^{-1}$ decreased by approximately half of its initial intensity, and the peak at $1630 \mathrm{~cm}^{-1}$ increased significantly in intensity. The decomposition rate of formic acid was much lower than that of toluene under the same conditions. Therefore, the benzene ring was relatively easily decomposed on the $\mathrm{H}-\mathrm{Y}$ surface compared to carboxylic acid. With reference to the IR spectra of $\mathrm{H}_{2} \mathrm{O}$ (Figure 8d), the peak at $1630 \mathrm{~cm}^{-1}$ with increased intensity was assigned to $\mathrm{H}_{2} \mathrm{O}$ the final product of formic acid oxidation.

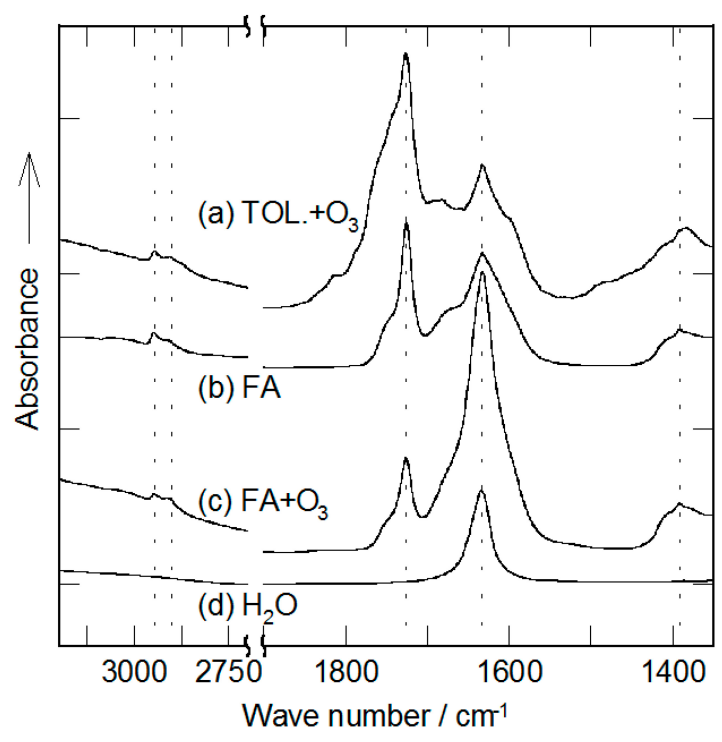

Figure 8. Infra-red spectra of (a) toluene adsorbed onto $\mathrm{H}-\mathrm{Y}(1)$ after introducing $\mathrm{O}_{3}$, (b) formic acid adsorbed onto $\mathrm{H}-\mathrm{Y}$, (c) after adducting $\mathrm{O}_{3}$, and (d) $\mathrm{H}_{2} \mathrm{O}$ adsorbed onto $\mathrm{H}-\mathrm{Y}$.

\section{Experimental Section}

\subsection{Decomposition of Toluene $\left(\mathrm{C}_{7} \mathrm{H}_{8}\right)$}

The configuration of the surface discharge reactor is shown in Figure 9a. A quartz tube (i.d.: 10 mm, thickness: $1.5 \mathrm{~mm}$ ) was used as the dielectric barrier. A spiral platinum wire coil (70 turns $/ 100 \mathrm{~mm})$ with a $0.3 \mathrm{~mm}$ diameter was placed in contact with the inner wall of the barrier tube. A piece of copper foil was wrapped around the outside of the barrier tube as the ground electrode; the outer electrode length was $100 \mathrm{~mm}$. 


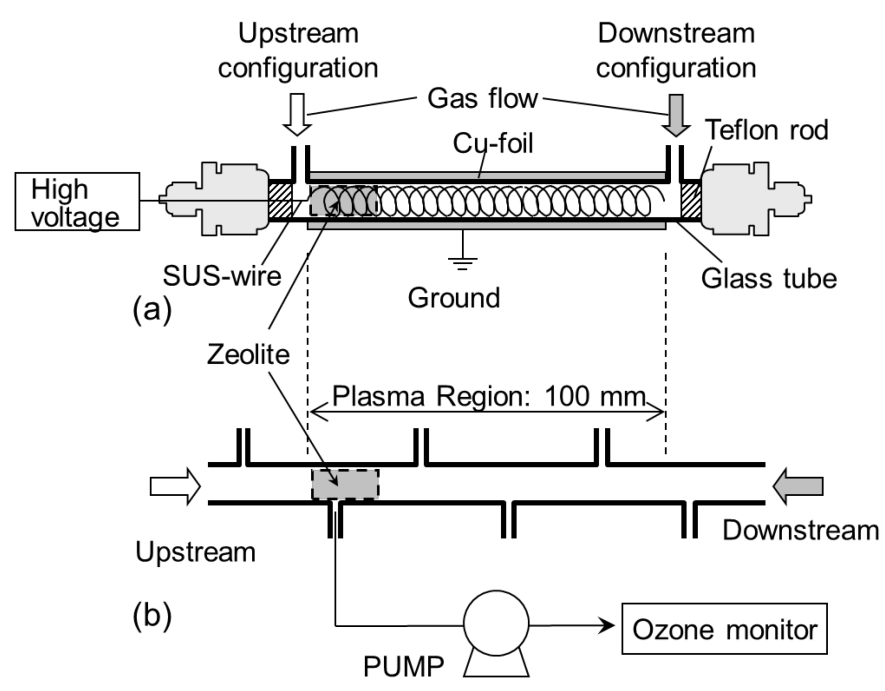

Figure 9. Configurations of (a) the zeolite hybrid reactor and (b) the reactor for monitoring the ozone distribution in the plasma region.

Zeolites $(1 \mathrm{~g})$ were packed into one end of the reactor. The reaction conditions were adjusted based on the flow direction and the position of the zeolites. The position of the zeolites was near the gas inlet in the upstream configuration and near the gas outlet in the downstream configuration.

The reactant gas consisted of $200 \mathrm{ppm}$ toluene $\left(\mathrm{C}_{7} \mathrm{H}_{8}\right), 0.5 \% \mathrm{H}_{2} \mathrm{O}$, and $20.0 \% \mathrm{O}_{2}$, with $\mathrm{N}_{2}$ making up the remaining fraction. It was fed at a flow rate of $500 \mathrm{~cm}^{3} / \mathrm{min}$ into the reactor, where a high AC voltage was applied between the two electrodes. The plasma energy was supplied using an AC high-voltage neon transformer (24 kHz, NEON M-5; Lecip Co., Gifu, Japan) and the plug-in power was measured using a digital power meter (WT110; Yokogawa Electric Co., Tokyo, Japan). The input power was 5 W.

The plasma was cycled four times in $160 \mathrm{~min}$ (off for $30 \mathrm{~min} \rightarrow$ on for $10 \mathrm{~min} \rightarrow$ off for $30 \mathrm{~min} \rightarrow$ etc.) (Figure 10), because cyclic operation improves energy efficiency by inducing periods of adsorption followed by plasma decomposition $[8,13]$. The concentrations of products such as $\mathrm{CO} x$ were consistent during each plasma period. The experiment was carried out at room temperature. Under plasma operation, the reactor temperature was increased to approximately $60{ }^{\circ} \mathrm{C}$.

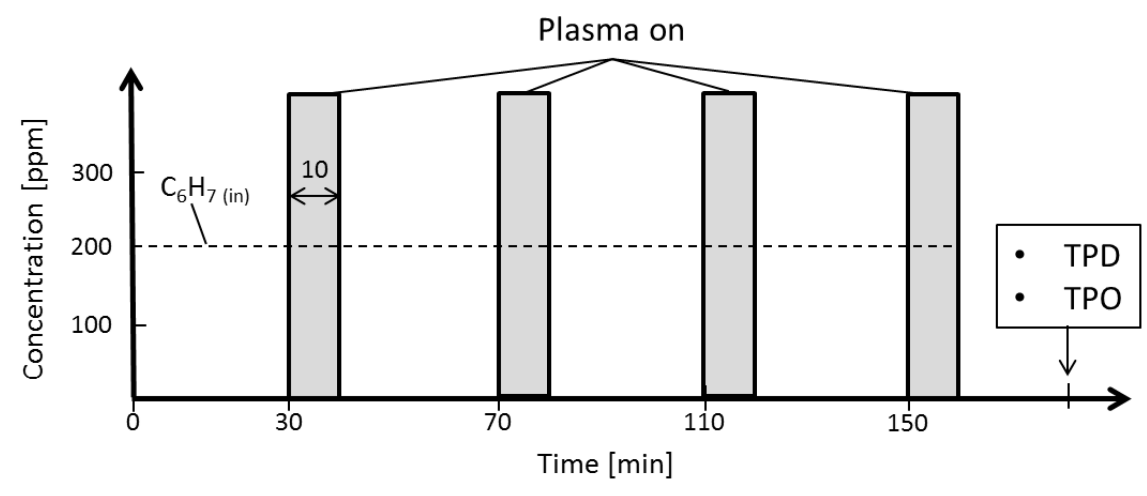

Figure 10. Plasma cyclic operation.

The effluent gas was monitored continuously using an FT-IR spectrometer (FTS135; Bio-Rad Laboratories, Hercules, CA, USA) equipped with a gas cell $\left(2.4 \mathrm{~m}\right.$ path, $125 \mathrm{~cm}^{3}$ volume; Infrared Analysis Inc., Anaheim, CA, USA) and the total amounts of the products were calculated from their 
integrated spectra. Under plasma operation, production of $\mathrm{N}_{2} \mathrm{O}$ and $\mathrm{HNO}_{3}$ was confirmed. The concentration of $\mathrm{N}_{2} \mathrm{O}$ was approximately $60 \mathrm{ppm}$. An accurate concentration for $\mathrm{HNO}_{3}$ could not be determined due to overlap of the FT-IR spectrum with that for $\mathrm{H}_{2} \mathrm{O}$. The amounts of adsorbed components on the zeolite were measured using temperature-programmed desorption and oxidation (TPD and TPO, respectively) after cyclical operation. For the TPD process, the zeolite was heated to $500{ }^{\circ} \mathrm{C}$ at a rate of $10{ }^{\circ} \mathrm{C} / \mathrm{min}$ and held at that temperature under $\mathrm{N}_{2}$ atmosphere. After the TPD process, the residual solid carbon was oxidized at $600{ }^{\circ} \mathrm{C}$ under synthetic air. Decomposition efficiency was calculated as follows:

$$
\mathrm{C}_{7} \mathrm{H}_{8} \text { decomposition }(\%)=\left(\mathrm{C}_{7} \mathrm{H}_{8 \text { in }}-\mathrm{C}_{7} \mathrm{H}_{8 \text { out }}-\mathrm{C}_{7} \mathrm{H}_{8 \mathrm{TPD}}\right) /\left(\mathrm{C}_{7} \mathrm{H}_{8 \text { in }}\right) \times 100
$$

where $\mathrm{C}_{7} \mathrm{H}_{8}$ in and $\mathrm{C}_{7} \mathrm{H}_{8}$ out are the total input and output of toluene, respectively. $\left(\mathrm{C}_{7} \mathrm{H}_{8}\right)_{\text {TPD }}$ is the amount of toluene desorbed from the TPD reactor, where the adsorbed toluene could be easily desorbed from the zeolite surface without noticeable decomposition. The carbon balance was estimated as follows:

$$
\text { Carbon balance }(\%)=\left(\mathrm{CO}_{2}+\mathrm{CO}+\mathrm{HCOOH}\right) / 7 \mathrm{C}_{7} \mathrm{H}_{8} \text { decomposition } \times 100
$$

Based on the relatively high carbon balance (Table 1), the influence of products other than those above, such as carbon deposition on the zeolite surface, was negligible. Thus, the product selectivity, where $X=\mathrm{CO}, \mathrm{CO}_{2}$, or $\mathrm{HCOOH}$, was calculated as follows:

$$
\text { Selectivity for } X(\%)=(X) /\left(\mathrm{CO}_{2}+\mathrm{CO}+\mathrm{HCOOH}\right) \times 100
$$

Four types of zeolites were used in this study: A Na-forms of faujasite (Na-Y), two H-forms of faujasite (H-Y), an H-form of mordenite (MOR), and an H-forms of ferrierite (FER). These samples molded into pellets were purchased from Tosoh Co. (Tokyo, Japan) and Nikki-Universal Co. Ltd. (Tokyo, Japan). Quite similar V-I patterns were observed for all zeolites.

\subsection{Measurement of the Ozone Concentration in the Reactor}

A reactor with six branch pipes (Figure 9b) was used to measure the $\mathrm{O}_{3}$ distribution in the plasma region at room temperature. The gas was sampled from each branch pipe using a diaphragm pump and $\mathrm{O}_{3}$ was measured using an ozone-monitor (PG-620H; Ebara Jitsugyo Co., Ltd., Tokyo, Japan). The zeolite pellets (1.0-3.0 g) were filled in the area indicated by the dotted line. Dry air $\left(20 \% \mathrm{O}_{2}\right.$ and $\left.80 \% \mathrm{~N}_{2}\right)$ was introduced into the reactor at a flow rate of $500 \mathrm{~cm}^{3} / \mathrm{min}$, and an input power of $2.0 \mathrm{~W}$ was applied.

\subsection{Infrared Measurement of the Chemical Species Adsorbed onto the Zeolites}

The IR spectra for chemical species adsorbed onto H-Y and FER were recorded using an FT-IR spectrometer (Spectrum 100; Perkin-Elmer Co. Ltd., Waltham, MA, USA) equipped with an IR cell for solid samples (Figure 11). The pellets were ground to a fine powder with an agate mortar and pestle, and the sample (0.043-0.044 g) was pressed into a thin disc $20 \mathrm{~mm}$ in diameter. The disc was inserted in the sample holder (Figure 11a) and the spectrum was measured using the transmission method. The sample could be moved to a heated position under desired gas flow conditions and to the measuring position at room temperature. The spectrum was measured at a resolution of $4.0 \mathrm{~cm}^{-1}$ and scan numbers of 200 using mercury cadmium telluride detector. 


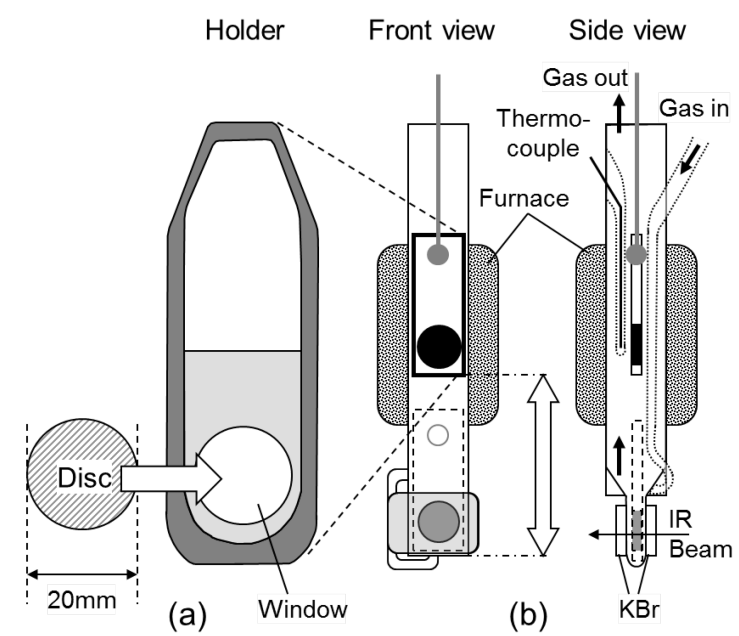

Figure 11. Configurations of (a) the sample holder and (b) the IR cell equipped with a furnace.

\section{Conclusions}

The reaction mechanism of the zeolite-plasma hybrid system for toluene decomposition was studied using gas and surface FT-IR analyses. The contributions of short-lived radicals and fast electrons to decomposition of adsorbed toluene were low. On the other hand, $\mathrm{O}_{3}$ directly decomposed toluene adsorbed in the inner areas of the zeolite micropore because it has a long life time. $\mathrm{O}_{3}$ provided the main mechanism of toluene decomposition in the zeolite-plasma hybrid system, unlike in metal-loaded zeolite-plasma systems. $\mathrm{CO}_{2}$ selectivity was not improved by use of the bare zeolite, because $\mathrm{H}$-Y zeolite does not retain active oxygen species on its surface through surface reactions of $\mathrm{O}_{3}$. Gas-phase $\mathrm{O}_{3}$ reacted with adsorbed toluene to form a ring cleavage intermediate that was slowly converted to formic acid. The decomposition rate of formic acid was much slower than that of toluene on the H-Y surface.

\section{Author Contributions}

Y.T., H.H.K., N.N. and A.O. designed the research; A.O. performed research; Y.T., H.H.K. and A.O. analysed data; Y.T. wrote, and all authors commented on the manuscript.

\section{Conflicts of Interest}

The authors declare no conflict of interest.

\section{References}

1. Oda, T. Non-thermal plasma processing for environmental protection: Decomposition of dilute VOCs in air. J. Electrostat. 2003, 57, 293-311.

2. Nunez, C.M.; Ramsey, G.H.; Ponder, W.H.; Abbott, J.H.; Hamel, L.E.; Kariher, P.H. Corona destruction-An innovative control technology for VOCs and air toxics. J. Air Waste Manag. 1993, 43, 242-247.

3. Yamamoto, T.; Futamura, S. Nonthermal plasma processing for controlling volatile organic compounds. Combust. Sci. Technol. 1998, 133, 117-133. 
4. Sobacchi, M.G.; Saveliev, A.V.; Fridman, A.A.; Gutsol, A.F.; Kennedy, L.A. Experimental assessment of pulsed corona discharge for treatment of VOC emissions. Plasma Chem. Plasma Process. 2003, 23, 347-370.

5. Ogata, A.; Ito, D.; Mizuno, K.; Kushiyama, S.; Gal, A.; Yamamoto, T. Effect of coexisting components on aromatic decomposition in a packed-bed plasma reactor. Appl. Catal. A 2002, 236, 9-15.

6. Park, D.W.; Yoon, S.H.; Kim, G.J.; Sekiguchi, H. The effect of catalyst on the decomposition of dilute benzene using dielectric barrier discharge. J. Ind. Eng. Chem. 2002, 8, 393-398.

7. Oda, T.; Yamashita, R.; Haga, I.; Takahashi, T.; Masuda, S. Decomposition of gaseous organic contaminants by surface discharge induced plasma chemical processing spcp. IEEE Trans. Ind. Appl. 1996, 32, 118-124.

8. Oh, S.M.; Kim, H.H.; Ogata, A.; Einaga, H.; Futamura, S.; Park, D.W. Effect of zeolite in surface discharge plasma on the decomposition of toluene. Catal. Lett. 2005, 99, 101-104.

9. Kim, H.H.; Oh, S.M.; Ogata, A.; Futamura, S. Decomposition of benzene using $\mathrm{Ag} / \mathrm{TiO}_{2}$ packed plasma-driven catalyst reactor: Influence of electrode configuration and Ag-loading amount. Catal. Lett. 2004, 96, 189-194.

10. Futamura, S.; Einaga, H.; Kabashima, H.; Lee, Y.H. Synergistic effect of silent discharge plasma and catalysts on benzene decomposition. Catal. Today 2004, 89, 89-95.

11. Ogata, A.; Einaga, H.; Kabashima, H.; Futamura, S.; Kushiyama, S.; Kim, H.H. Effective combination of nonthermal plasma and catalysts for decomposition of benzene in air. Appl. Catal. B 2003, 46, 87-95.

12. Magureanu, M.; Mandache, N.B.; Parvulescu, V.I.; Subrahmanyam, C.; Renken, A.; Kiwi-Minsker, L. Improved performance of non-thermal plasma reactor during decomposition of trichloroethylene: Optimization of the reactor geometry and introduction of catalytic electrode. Appl. Catal. B 2007, 74, 270-277.

13. Han, S.B.; Oda, T.; Ono, R. Improvement of the energy efficiency in the decomposition of dilute trichloroethylene by the barrier discharge plasma process. IEEE Trans. Ind. Appl. 2005, 41, 1343-1349.

14. Hakoda, T.; Matsumoto, K.; Mizuno, A.; Kojima, T.; Hirota, K. Catalytic oxidation of xylene in air using $\mathrm{TiO}_{2}$ under electron beam irradiation. Plasma Chem. Plasma Process. 2008, 28, 25-37.

15. Rousseau, A.; Meshchanov, A.V.; Roepcke, J. Evidence of plasma-catalyst synergy in a low-pressure discharge. Appl. Phys. Lett. 2006, 88, doi:10.1063/1.2164915.

16. Kim, H.H.; Kim, J.H.; Ogata, A. Microscopic observation of discharge plasma on the surface of zeolites supported metal nanoparticles. J. Phys. D 2009, 42, 135210.

17. Ogata, A.; Ito, D.; Mizuno, K.; Kushiyama, S.; Yamamoto, T. Removal of dilute benzene using a zeolite-hybrid plasma reactor. IEEE Trans. Ind. Appl. 2001, 37, 959-964.

18. Oh, S.M.; Kim, H.H.; Einaga, H.; Ogata, A.; Futamura, S.; Park, D.W. Zeolite-combined plasma reactor for decomposition of toluene. Thin Solid Films 2006, 506, 418-422.

19. Sano, T.; Negishi, N.; Sakai, E.; Matsuzawa, S. Contributions of photocatalytic/catalytic activities of $\mathrm{TiO}_{2}$ and $\mathrm{g}-\mathrm{Al}_{2} \mathrm{O}_{3}$ in nonthermal plasma on oxidation of acetaldehyde and co. J. Mol. Catal. A Chem. 2006, 245, 235-241.

20. Bulanin, K.M.; Lavalley, J.C.; Lamotte, J.; Mariey, L.; Tsyganenko, N.M.; Tsyganenko, A.A. Infrared study of ozone adsorption on $\mathrm{CeO}_{2}$. J. Phys. Chem. B 1998, 102, 6809-6816. 
21. Einaga, H.; Futamura, S. Catalytic oxidation of benzene with ozone over mn ion-exchanged zeolites. Catal. Commun. 2007, 8, 557-560.

22. Teramoto, Y.; Kim, H.H.; Ogata, A.; Negishi, N. Study of plasma-induced surface active oxygen on zeolite-supported silver nanoparticles. Catal. Lett. 2013, 143, 1374-1378.

23. Kim, H.H.; Sugasawa, M.; Hirata, H.; Teramoto, Y.; Kosuge, K.; Negishi, N.; Ogata, A. Ozone-assisted catalysis of toluene with layered ZSM-5 and Ag/ZSM-5 zeolites. Plasma Chem. Plasma Process. 2013, 33, 1083-1098.

24. Einaga, H.; Ogata, A. Benzene oxidation with ozone over supported manganese oxide catalysts: Effect of catalyst support and reaction conditions. J. Hazard Mater. 2009, 164, 1236-1241.

25. Kwong, C.W.; Chao, C.Y.H.; Hui, K.S.; Wan, M.P. Catalytic ozonation of toluene using zeolite and MCM-41 materials. Environ. Sci. Technol. 2008, 42, 8504-8509.

26. Chao, C.Y.H.; Kwong, C.W.; Hui, K.S. Potential use of a combined ozone and zeolite system for gaseous toluene elimination. J. Hazard Mater. 2007, 143, 118-127.

27. Sullivan, R.C.; Thornberry, T.; Abbatt, J.P.D. Ozone decomposition kinetics on alumina: Effects of ozone partial pressure, relative humidity and repeated oxidation cycles. Atmos. Chem. Phys. 2004, 4, 1301-1310.

28. Li, W.; Gibbs, G.V.; Oyama, S.T. Mechanism of ozone decomposition on a manganese oxide catalyst. I. In situ raman spectroscopy and ab initio molecular orbital calculations. J. Am. Chem. Soc. 1998, 120, 9041-9046.

29. Li, W.; Oyama, S.T. Mechanism of ozone decomposition on a manganese oxide catalyst. 2. Steady-state and transient kinetic studies. J. Am. Chem. Soc. 1998, 120, 9047-9052.

30. Ogata, A.; Shintani, N.; Mizuno, K.; Kushiyama, S.; Yamamoto, T. Decomposition of benzene using a nonthermal plasma reactor packed with ferroelectric pellets. IEEE Trans. Ind. Appl. 1999, 35, 753-759.

31. Kuroki, T.; Fujioka, T.; Okubo, M.; Yamamoto, T. Toluene concentration using honeycomb nonthermal plasma desorption. Thin Solid Films 2007, 515, 4272-4277.

(C) 2015 by the authors; licensee MDPI, Basel, Switzerland. This article is an open access article distributed under the terms and conditions of the Creative Commons Attribution license (http://creativecommons.org/licenses/by/4.0/). 